Research Article

\title{
A Comparative Analysis of Strategic Values of Four Silk-Road International Transport Corridors Based on a Fuzzy Integral Method with Comprehensive Weights
}

\author{
Chengfu Wang, ${ }^{1,2}$ Chengfeng Huang $\mathbb{D}^{1},{ }^{1}$ Haichang Guan, ${ }^{1}$ and Tao Zeng ${ }^{1}$ \\ ${ }^{1}$ School of Economics and Management, Chongqing Jiaotong University, Chongqing 400074, China \\ ${ }^{2}$ School of Management, Chongqing University of Technology, Chongqing 400054, China \\ Correspondence should be addressed to Chengfeng Huang; 981327204@qq.com
}

Received 27 July 2020; Revised 31 October 2020; Accepted 6 November 2020; Published 24 November 2020

Academic Editor: Tingsong Wang

Copyright ( $\odot 2020$ Chengfu Wang et al. This is an open access article distributed under the Creative Commons Attribution License, which permits unrestricted use, distribution, and reproduction in any medium, provided the original work is properly cited.

\begin{abstract}
This paper carries out a comparative analysis of the strategic values of four silk-road international transport corridors, "ChinaPakistan-Iran-Turkey" (CPIT), "China-Mongolia-Russia" (CMR), "Bangladesh-China-India-Myanmar" (BCIM), and "ChinaSingapore-Egypt-Greece" (CSEG). These corridors aim to reactivate the Northwest, North, South, and Marine Silk Road during the period of the "Belt and Road" (B\&R), reflect China's overarching strategic goal of "furnishing land-sea internal and external linkage and achieving east-west mutual aid," and possess important strategic values. To facilitate the comparison, this paper constructs a hierarchical model and evaluation index system for assessing the strategic value of international transport corridors (SVITC). From China's perspective, this paper uses a fuzzy integral method with comprehensive weights to evaluate and compare the SVITC of the four international corridors as fuzzy integrals can handle interdependent indices and comprehensive weights can accommodate both subjective and objective weights. In the evaluation process, we first clarify the strategic attributes and characteristics of each corridor and identify its corresponding missions so that the overseas infrastructure projects along the four corridors can be carried out smoothly. By assessing their strategic values and ranking them accordingly, we offer the policy maker with useful information to prioritize investment opportunities and deploy limited resources in the construction of these corridors. Finally, this comparative study identifies the weaknesses and strengths in different corridors, which allow them to learn from each other, make joint progress, and strengthen linkages and integrations, thereby providing a set of feasible solutions for the construction of $\mathrm{B} \& \mathrm{R}$ international corridors.
\end{abstract}

\section{Introduction}

As an extension of China's long maritime and land borders, its historical Silk Road consists of four international transport corridors, including the Northwest Oasis, Northern Grassland, South (Southwest), and Maritime Silk Road. These four corridors correspond to four exit routes located in Xinjiang, Inner Mongolia, Yunnan, and Tibet, and the eastern coastline as well as their extension lines, respectively. Stretching for thousands of miles and lasting for thousands of years, the Silk Road carries out China's trade and cultural interactions with different regions, countries, nations, and districts, which has important strategic value since ancient times. Under the current "Belt and Road" (B\&R) initiative, the conception or construction of the four international transport corridors, "China-Mongolia-Russia" (CMR), "Bangladesh-China-India-Myanmar" (BCIM), "China-Pakistan-Iran-Turkey" (CPIT), and "China-SingaporeEgypt-Greece" (CSEG), aims to reinvigorate the historical Silk Road in the north, southwest, northwest, and sea, respectively. They constitute an important core of the B\&R international transport corridors and embody the grand strategic goal of "furnishing land-sea internal and external linkages and achieving east-west mutual aids." In the era of combating deglobalization, trade friction, and rampant populism, China proposes its own solution to promote globalization and free trade. By providing the public goods of international infrastructure, China lays out the foundation for the world to maintain interactions and communications, which has great 
strategic values for both China and partner nations along the corridors. Moreover, megainfrastructure projects are a Chinese tradition; ranging from the Great Wall as an ancient defense structure to Grand Canal as a significant water highway connecting Beijing and Hangzhou and the more recent ThreeGorge Dam on the Yangtze River. The aforesaid megaprojects were constructed on Chinese territory. On the contrary, most of the infrastructure construction along the Silk Road will take place beyond China's borders and, thus, will bring additional challenges outside its control [1]. At the same time, despite the establishment of the Silk Road Fund and the proposal of the Asian Infrastructure Investment Bank, there remains a huge financial gap in international infrastructure construction projects, which often requires enormous investments. For example, the Asian Development Bank (ADB) estimated Asia's infrastructure funding gap at a massive $\$ 8$ trillion through 2020 [2]. Given the aforesaid challenges, firstly, we clarify the strategic attributes and characteristics of the four corridors and identify their corresponding missions so that concrete suggestions can be offered to facilitate the smooth construction of overseas infrastructure along these corridors. Secondly, we put forward an effective evaluation framework to assess the strategic value of the four corridors, thereby obtaining their relative ranking. Given the huge funding gap in B\&R infrastructure investments, this research contributes to long-term overall planning and prioritization of different investment opportunities, thereby allowing the policy makers to make more informed decisions in funding allocation. Finally, the comparison among the corridors allows them to learn from each other, make joint progress, and strengthen linkages and integrations, thereby providing a set of feasible solutions for the construction of $\mathrm{B} \& \mathrm{R}$ international corridors.

In recent years, research on transportation corridors has been carried out from different angles such as economy, risk, and security. In particular, the studies on the economic impact of corridors are the primary concern. From the perspective of user benefits, Regmi and Hanaoka utilized a time-cost-distance approach to assess and compare the performance of transport corridors [3]. This is a direct economic result. Berechman et al., Vinokurov and Tsukarev, and Donaldson evaluated not only direct but also indirect economic results such as the general economic development, including trade flows, economic welfare, and other issues [4-6]. Berg et al. and Roberts et al. studied the impact of large transport infrastructure projects from a wider perspective covering economic performance, social benefits, environmental quality, and other issues [7-11]. Hahm and Raihan suggested maximizing a wider economic impact of the B\&R economic belt by accounting for social and environmental risks [12]. Chang and Khan considered other issues such as maritime cooperation and security [13].

To the best of the authors' knowledge, limited research is conducted on assessing the SVITC. Wang and Zhu characterized strategic values from different angles such as political diplomacy, security, and economy and assessed the SVITC of the CMR international corridor from the perspectives of China, Mongolia, and Russia, respectively [14]. From a qualitative perspective, Lin examined the impact of the China-Nepal-India economic corridor on China's internal affairs, diplomacy, economy, energy, and so on, thereby illuminating the necessity and feasibility of the construction as well as its content and path [15]. In essence, this transport corridor is the Tibet exit route in addition to the Yunnan exit route of the Southern Silk Road. From the perspectives of China and Pakistan, Li and Sun qualitatively described the strategic value of the China-Pakistan Economic Corridor (CPEC) by considering geopolitics, economy, and security [16]. Zubir and Malik analyzed the strategic value of key nodes from military and economic value perspectives from the standpoint of the Strait of Malacca and the Gwadar Port, respectively [17, 18]. Yang et al. quantitatively evaluated the strategic value of the Ryukyu Island, oil and gas resources in the South China Sea, islands and reefs in the South China Sea and other key nodes, and regions or specific resources in the marine international transport corridor. Their research takes a nonnational angle to conduct strategic value assessment [19-21]. Yang et al. carried out a qualitative analysis from the perspective of geopolitics and route trend of BCIM, which is a particular aspect of SVITC $[22,23]$.

In summary, current studies about transport corridors have gradually extended from a purely economic perspective to a wider economic perspective including society, environment, and security. Firstly, following this idea, research can be further extended from the broader perspective to a systematic level of the strategic value that accounts for political, military, and cultural aspects. Secondly, current studies on the SVITC are mostly carried out from a single channel or focus on a key node in a qualitative manner. In contrast, this research takes the whole network of the Silk Road as our subject and considers the four international corridors in a much bigger scope. When assessing their SVITC and carrying out the comparative analysis, we rely on a quantitative framework. This research helps us to obtain an overall assessment of B\&R projects along the four corridors.

\section{An Evaluation Index System and Hierarchy Theory of Assessing SVITCs}

2.1. Construction of an Evaluation Index System of SVITCs. A narrow definition of international transport corridors is a route network that crosses the borders of two or more sovereign countries, including roads, railways, air transport, waterways, and pipelines. An international corridor provides an infrastructure and platform for the relevant nations to maintain interactions and communications. Moreover, as an international public product, it often has the characteristics of national interest [24]. Therefore, the research subjects of international transport corridors are actually the sovereign countries along the route, which is a scope of a national perspective. From this point of view, the "first existence" of strategies is national interests [25]. The key to success or failure of a grand strategy is the attempt by different powers to integrate their overall political, economic, and military objectives and, thus to preserve their long-term national interests [26]. It is clear that national interests are the essence and key of a strategy. In addition, a value is a degree to which an object meets the needs of the 
subject through their interaction. Therefore, the SVITC is the degree to which a sovereign state along the route meets its national interests via interaction with other countries along or around the route with the aid of the route network of the international transport corridor.

As Waltz put it, "national interests are a small number of big and important things" [27]. More specifically, national interests refer to the main benefits and rights pursued by a nation, which reflect the collective needs and interests of its citizens and various interest groups. National interests are essentially a comprehensive weighted value that accounts for both objective benefits (such as territorial integrity, economic strength, and military power) and subjective interests (such as image and self-esteem) [28]. From the perspective of needs and desires, national interests can be defined from both a material and spiritual angle. Materially, a country needs security and development; spiritually, it needs respect and recognition from the international community [29]. According to Kortunov's holistic approach to identifying sources of national interests, each country has to fulfill a historical mission. Typically, a mission is deeply rooted in the culture, history, and geopolitical position of a particular country, which cannot be freely chosen, changed, or rejected. A country that cannot follow its mission is doomed to decline and eventually collapse [30]. Different cultural traits can influence a country's subjective definition of its objective national interests [31]. Based on the aforesaid viewpoints, one can see that national interests, as a comprehensive weighted value, are related to national sovereignty, economy, military, security, society, culture, political diplomacy, and so on. At the same time, it needs to make trade-offs for the overlapped and partially overlapped indices. For instance, national sovereignty is also a comprehensive and overlapping concept covering security, military, economy, politics, culture, and society, among others, where national security can be roughly gauged by national military. Moreover, an international corridor has to consider its geographical limits, but a well-connected network helps to reduce travel time and expand the scope. As such, this paper confines politics to a geopolitical consideration.

Given the aforesaid analysis, this research first defines an evaluation index system to evaluate SVITC as a comprehensive weight of cultural, geopolitical, social, military, and economic values, denoted by $C$ (Culture), $P$ (Politics), $S$ (Society), $M$ (Military), and $E$ (Economy) in Figure 1 below.

2.2. A Hierarchy Theory of SVITC. SVITC research on a corridor considers it as an interactive carrier system to meet national interests of sovereign countries along the corridor. As mentioned earlier, national interests reflect the collective needs and desires of its citizens and various interest groups. From a micropoint of view, countries are made up of people. State behavior is bounded rational behavior of a group, and state needs can be regarded as demands from the vast majority of citizens in a country [32]. Therefore, to decompose national interests into a citizen level, one can see that they presumably integrate individual demands and desires and, hence, the underlying logic conforms to Maslow's theory of hierarchy needs, which, from the bottom to the top, covers physiological (survival) (seeking basic necessities of life), safety (seeking security through order and law), belongingness and love needs (seeking affiliation with a group), esteem (seeking esteem through recognition or achievement), and self-actualization needs (seeking fulfillment of personal potentials) [33]. In parallel, this paper models the demands and desires of the national interests as the five levels of economy, military, society, geopolitics, and culture following Maslow's theory. This mapping matches the survival, safety, belongingness, respect, and self-realization needs at a national level. To project national interests into SVITC, we thus construct a hierarchical model of SVITC as shown in Figure 2. At the same time, as the right of Figure 2 indicates, national development can be divided into three stages, the subsistence stage (covering economy and military values), the well-off stage (including social and geopolitical values), and the wealthy stage (corresponding to cultural value).

Figure 2 clearly shows that the relationship between the values in the evaluation index system of SVITC is not a parallel but a hierarchical structure. The general idea of Maslow's theory is that the needs of the lower level should be satisfied prior to those of the higher levels. This is not only true at an individual level but also at a national level though exceptions exist as needs are also related to the characteristics of the endowment rooted in national cultural genes. Lower level needs are foundational and subsistent, which offer guarantees for higher-level needs. Among them, national security is generally regarded as a red line and is inviolable. When a country's territorial integrity is threatened, it will normally vow to defend at any expense. Furthermore, the foundations must be strong to furnish solid support for upper-level needs. At a national level, its economy and military determine the stability of the upper structure. At the same time, higher-level needs often set up a framework for lower-level needs, especially the tradition of culture, which is deeply rooted in the collective subconsciousness of different countries and has strong inertia. The needs across different levels or at the same level can promote or contain each other. In short-term emergencies, a certain value may be sacrificed in exchange for another value. For example, during the COVID-19 pandemic, China took the initiatives to lock down Wuhan and the whole country for an extended period of time. This extraordinary measure is to sacrifice short-term economic value for social value, namely, to contain the virus spread and protect the lives, health, and well-being of all its citizens. At the same development stage, such as the economy and the military value (subsistence stage), without sacrificing the red line of national security, a dynamic balance should be struck by balancing their mutual restraints and promotion. In other words, the economy cannot be damaged by an unconstrained arms race, but strategic military deterrence can safeguard national security and create a stable and secure environment for economic development. However, no matter how to promote and restrain each other across different levels or at the same development stage, these values collectively serve national interests of sovereign states and aim to achieve overall utility maximization of national interests in a dynamic environment. 


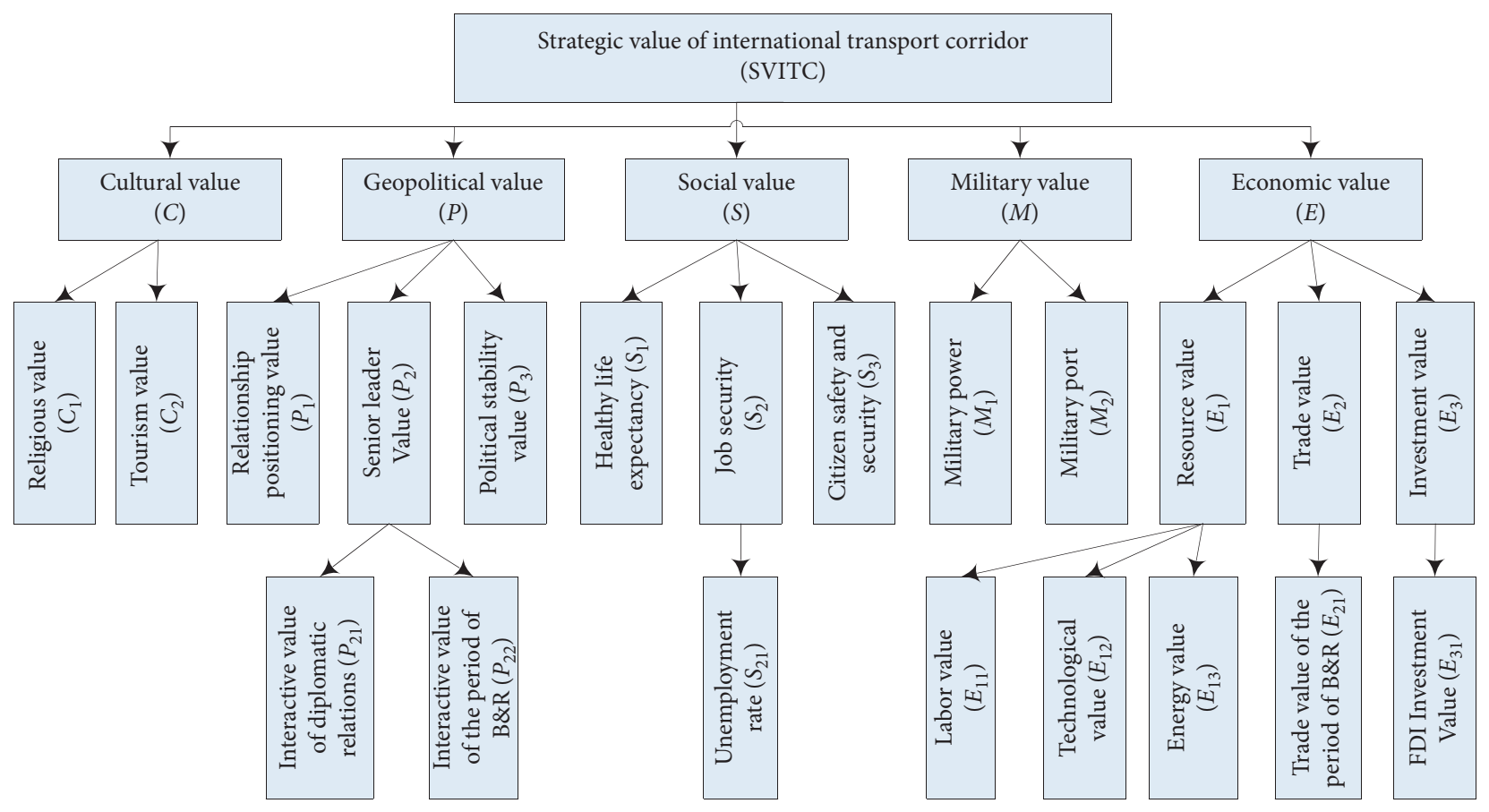

Figure 1: An evaluation index system of SVITC.

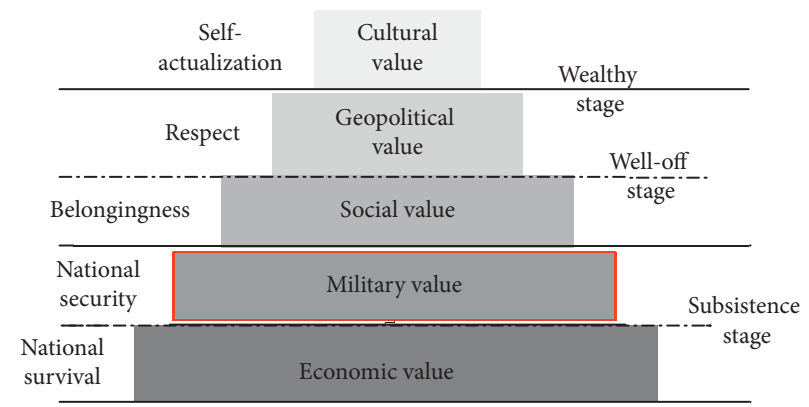

FIgURe 2: A hierarchical model of SVITC.

Different development stages of the same country have different utilities across the five value needs, which require the evaluation system to be adjusted dynamically. This means that different weights are to be assigned to the five values as per distinct development stages. Moreover, in the same period, different countries usually have different preferences to the five values due to their distinct stages of development and unique needs. Even at the same stage of development, different countries may still assign different weights to these values due to their diverse cultures and development modes. For example, the aforesaid national security is generally sacred and inviolable and regarded as the red line. However, Satmar Jews would argue that the establishment of a modern secular Zionism state is inconsistent with their religious doctrine. They believe that the fate of the Jews lies in the Jewish diaspora and, hence, strongly opposes Zionism. Therefore, in a comprehensive evaluation of SVITC, it is necessary to assess the development stage and cultural tradition of the sovereign states associated with a corridor and assign proper weights to the five values accordingly.

\section{Background Information of the Four Silk- Road International Transport Corridors}

3.1. The Four Corridors Connecting Ancient and Modern Times. The four international transport corridors studied in this research connects China with the rest of the world along with four directions, which correspond to the four exits of the ancient Silk Road.

The CPIT, which takes a land exit in Xinjiang located in northwest China, inherits and aims to reinvigorate the Northwest Oasis Silk Road, which was the most influential one in history among the ancient Silk Roads. The key countries involved in this corridor are China, Pakistan, Iran, and Turkey. About two thousand years ago, they were connected by the Northwest Oasis Silk Road, corresponding to the four major historical empires of Han-Kushan-Parthian-Roman [34]. By 
capitalizing on Turkey's unique geographical location of Eurasian crossroads, the future CPIT can be either retracted or extended to the northwest through Bulgaria to Serbia, where it joins the transport artery of the China-Europe land-sea express line in Belgrade (Serbia). In this case, it forms a closed loop with the CSEG of the Maritime Silk Road.

The CMR aims to revive the Northern Grassland Silk Road, which is a grassland zone stretching between the 40th-50th parallel north and the earliest communication channel for Eurasian nations. The terrain is wide and flat, and the route is largely natural. Unlike the other three routes that need to cross mountains or over the sea, this route is unimpeded. The natural corridor had witnessed the three western expeditions of the Mongolian army under Genghis Khan, Badu, and Hulagu. Moreover, the Treaty of Kiakhta between China and Russia in 1728 established trading cities along the border and engendered the Kiakhta Tea Road. The CMR corresponds to the exit route of Inner Mongolia in north China, which goes through Mongolia and, then to Russia. Reviving this corridor will allow China, Mongolia, and Russia to better collaborate with each other and pave the road for continued prosperity in the new era.

The BCIM, as a representative of the Southern Silk Road, takes the south exit route via Yunnan. The scope of the Southern Silk Road also includes the China-Nepal -India International corridor, corresponding to the Tibet exit. These two routes are the main connections between the south (southwest) China and the outside world for many years in history. In ancient times, Yunnan was locked by high mountains and deep valleys and was beyond the reach of the Central Plains Dynasties in China owing to limited traffic routes. Dali was conquered by Mongolia forces in 1253, and Yunnan was integrated into the Central Plains Dynasty since then. Before its integration into the Yuan Dynasty, Yunnan used shell currency, which was consistent with the source, type, and counting unit of shell coins in South and Southeast Asia. This coincidence clearly shows that Yunnan had been sharing a common regional market with South and Southeast Asia for a long historical period [35]. During World War II, Japan tried to completely cut off China's material supply lines by blocking the coastline in southeast China with an extension to the Indochina Peninsula and destroying the Yunnan-Vietnam Railway. To counter this effort, the Yunnan-Burma Road completed in 1939 and the Stilwell Road started in 1945 became China's "anti-Japanese lifeline" in times of crisis. These historical clues are of great reference values for the resurrection and planning of the BCIM.

The CSEG, as a star passageway on the Maritime Silk Road, is the exit route for China's eastern coastline. It departs from the Yangshan Port of Shanghai and reaches the Piraeus Port in Greece. The countries along the route include China, Singapore, Egypt, and Greece, as well as surrounding nations. The starting and ending points of the ancient land-based Silk Roads are connected by the Maritime Silk Road. The three ancient civilizations of China, Egypt, and Greece and the rising star of Singapore have learned from each other. As the southern gateway of Europe, the Piraeus port is conceived to be the bridgehead of sea-land multimodal transport in the construction of the China-Europe land-sea express line. Upon its completion, the CSEG, after arriving at the Piraeus port, will be connected to the "Iron Silk Road," part of the China-Europe land-sea express line, and pass through Skopje (Macedonia), Belgrade (Serbia) in succession, and then, head north to Budapest (Hungary). This route will quickly connect to the hinterland of Europe and be integrated with the other "Iron Silk Road" of CPIT in Serbia with the potential of directly benefiting over 32 million people.

3.2. Comparative Spatial Structures of Orientation and Transportation Indexes of the Four Corridors. The approximate spatial structures of orientations for the four international transport corridors (labelled as T1, T2, T3, and T4) are shown in Figure 3. Table 1 displays the comparative transportation metrics of the four corridors along with their acronyms and labels T1, T2, T3, and T4. Due to the vast territory of China, if a starting point is selected at a different location, the total transportation distance will change dramatically. For example, if the starting point of Urumqi (T1) is moved to Shanghai (T4), the distance of T1 will increase by more than 4,000 kilometers and become 11,500 kilometers. Therefore, the transportation distance of the four corridors will be calculated in such a way that the starting point is chosen as the provincial capital city of the corresponding exit of a particular corridor. This is also in line with the open-up reality of inland borders and coastal areas of China. First, the border areas should not only be opened to the outside world but also integrated into the comprehensive domestic transport network to promote the overall integration process.

3.2.1. The Spatial Structures of Orientations. As shown in Figure 3, the four corridors represent the Northwest, North, Southwest, and East exit passageways starting from Urumqi, Hohhot, Kunming, and Shanghai, respectively. Here, T3 is worth further explanations. At present, several plans have been proposed for the route of T3. Figure 3 selects the China-Myanmar railway plan based on the former Yunnan-Burma Road and chooses the west line of the China-Myanmar "herringbone" railway, namely, Kunming-Dali-Ruili-Lashio-MandalayMarqui-Kyaukpyu Port (about 1,549 km). Then, the Kyaukpyu Port is connected to the Chittagong (Bangladesh) and the Kolkata Port (India) by a waterway. The Kyaukpyu Port on the west line has an absolute advantage in water depth than the Yangon Port on the east line. At present, China and Bangladesh are not connected by land. Furthermore, trades between China and Bangladesh are mainly transported by waterways, and $90 \%$ of cargo shipment between China and India goes through waterways at the Kolkata Port and the Mumbai Port. Therefore, we select the "railway + waterway" intermodal transportation route for T3 in this paper. The railway stretches 1,549 kilometers and the waterway extends for 1,074 kilometers, totaling about 2,623 kilometers. 


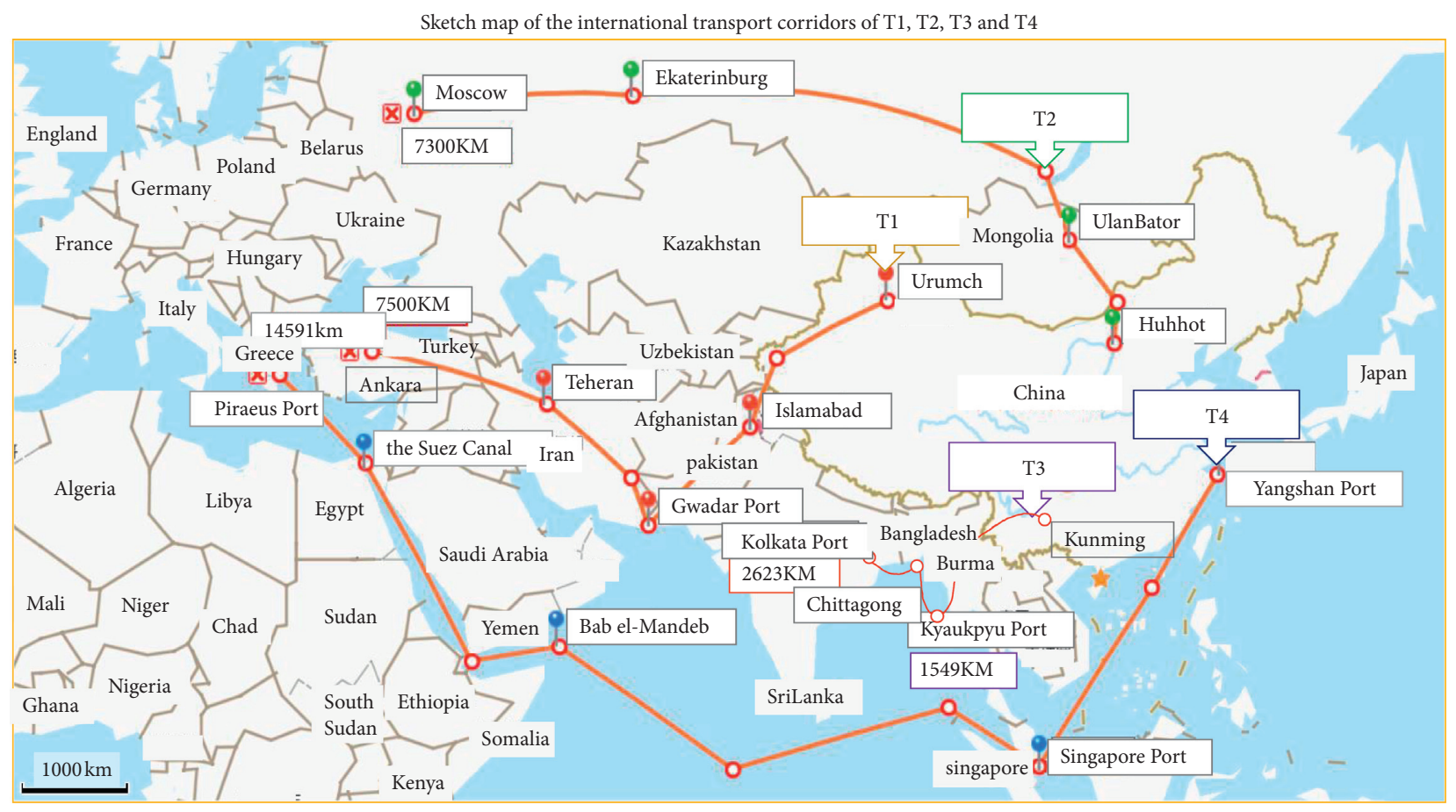

FIgURE 3: Corridors orientation roadmap of T1, T2, T3, and T4.

TABle 1: Comparative metrics of T1, T2, T3, and T4.

\begin{tabular}{|c|c|c|c|c|c|c|c|c|}
\hline Routes & Name & $\begin{array}{c}\text { Shipment } \\
\text { distance }(\mathrm{km})\end{array}$ & $\begin{array}{l}\text { Shipment } \\
\text { time (day) }\end{array}$ & $\begin{array}{c}\text { Border Clearance } \\
\text { efficiency(1) }\end{array}$ & $\begin{array}{c}\text { Cost } \\
(\mathrm{USD} / 40 \mathrm{ft})(2) \\
\end{array}$ & $\begin{array}{c}\text { Transport } \\
\text { infrastructure(3) }\end{array}$ & $\begin{array}{l}\text { The exit } \\
\text { region }\end{array}$ & Corridor form \\
\hline CPIT & $\mathrm{T} 1$ & 7500 & 114 & 37 & 4125 & 54.36 & Xinjiang & Railway \\
\hline CMR & $\mathrm{T} 2$ & 7300 & $10(5)$ & 33 & 4105 & 46.6 & $\begin{array}{l}\text { Nei } \\
\text { Mongol }\end{array}$ & Railway \\
\hline BCIM & T3 & 2623 & $4(6)$ & 41 & 9557 & 54.25 & Yunnan & Railway + waterway \\
\hline CSEG & $\mathrm{T} 4$ & 14591 & 218 & 53 & $1400(9)$ & 70.46 & Shanghai & Sea lane \\
\hline
\end{tabular}

(1)Data source: index 7.07 of "Global Competition Report 2019" from World Economic Forum. The countries along each route take the average after summarizing, and the higher scores indicate the higher efficiency of border clearance. (2)Data source: China Ministry of Commerce, "Yuxinou's freight rate dropped to sea level," http://www.mofcom.gov.cn/article/resume/n/201505/20150500961358.html, accessed on Feb. 20, 2020. Assuming that T1 and T2 will be high-speed rail channels in the future, the unit price of the Yuxinou high-speed rail in this article is USD 0.55/km/40 ft. Therefore, according to the distance, the costs of T1 and T2 are, respectively, estimated as USD 4125/40 ft and USD 4105/40 ft. (3Data source: average weighting of indexes 1.01-1.04 of "Global Competition Report 2019" from World Economic Forum. The countries along each route take the average after summarizing, and the higher scores indicate the higher connectivity of transport infrastructure. (4) We assume that T1 is planned as high-speed rail channel, and the train speed and customs clearance time are similar to those of Yuxinou ( $11000 \mathrm{~km}, 15$ days), the estimated transport time of T1 is $7500 / 11000 \times 15=10.2$ days, and the estimated transport time is 11 days. (5) The same as above, $7300 / 11000 \times 15=9.95$ days, the estimated transportation time of T2 is about 10 days. (6) Because T3 selects the "railway + waterway" intermodal transportation route, the estimated transportation time is divided into two sections, that is, the railway section is the same as Yuxinou's standard. The waterway transport section is estimated based on T4 as the reference value, $1549 / 11000 \times 15+1074 / 14591 \times 21=3.65$ days, the valuation is 4 days. (7)The same as above, the transportation costs of T3 are estimated in two sections, that is, the railway section is estimated based on Yuxinou's standard, and the waterway section is estimated based on the T4. $1549 \times 0.55+1074 / 14591 \times 1400=$ USD $955 / 40 \mathrm{ft}$. (8) This data is calculated based on the Cosco Shipping Group's operating routes on this channel, which is calculated by tracking its regular routes in the trans-Pacific-Indian Ocean route (Asia-Europe).9 Data source: "the shipping cost from Shanghai to Piraeus Port is USD1 400/40 ft," http://www.daili56.com/hyunfeix/?9-2070.html, accessed on Feb. 20, 2020.

\subsubsection{Comparison of Key Transportation Metrics.} Referring to Table 1 and Figure 3, we can see that there are three passages for China to go south into the Indian Ocean. The fastest passage is T3. Kunming-Kyaukpyu Port is only $1549 \mathrm{~km}$ on land. Following the east line of the ChinaMyanmar "herringbone" railway, China may lift the barrier to build a high-speed rail along the west line with Myanmar and restart the "Memorandum of Understanding on the Muse-Kyaukphyu Railway Transportation System Project" signed earlier in 2011 to support the Kyaukpyu Port which is under construction. Obviously, this helps to convert it into an integrated "railway + water + pipe" hub. The natural water depth of the Kyaukpyu Port is 24 meters and can accommodate cargo ships in the range of 250,000-300,000 tons, surpassing the Gwadar Port (100,000-200,000 tons) on T1, the Suez Canal (250,000 tons), and the Malacca Strait (200,000 tons) on T4. If the port and the feeding infrastructure projects are completed, it will not only be able to 
easily meet the docking needs of cargo ships on the Suez Canal route but also satisfy the berthing needs of large or super-large cruise ships (between 200,000 and 300,000 tons) detouring the Cape of Good Hope route, In this case, these vessels will be able to land directly in the Indian Ocean without continuing eastbound through the Strait of Malacca or bypassing the Sunda Strait. This can not only shorten the transportation distance but also hedge the risk of relying heavily on the Strait of Malacca, thereby seamlessly connecting to the existing Sino-Burmese oil and gas pipelines. This move will greatly change China's energy supply landscape. Since 2014, Japan offered to spend 7.8 billion yen (about 472 million yuan) to assist Myanmar in building a railway for free, which effectively obstructed the construction of the west line of the China-Myanmar "herringbone" railway, resulting in the suspension of the project till now. Therefore, this development, on the flip side, proves the strategic significance of this west line to China. T1 is the second fastest way to the Indian Ocean. The distance from Xinjiang to the Gwadar Port is about 3,000 km, namely, the CPEC. As a flagship B\&R project, its overall progress is smooth and moves the fastest. The Gwadar Port has already started sailing in 2016, and the regular container liner route was opened in 2018. Clearly, it has changed from a blueprint to reality in contrast to the stagnation and on-and-off of the Kyaukphyu Port.

From the perspective of the travel distance of the four corridors, T3 is the shortest about 2,623 km, but the west line of the China-Myanmar "herringbone" railway remains at the planning stage. Because of its importance, it can be predicted that more obstacles may arise in the future. The distances of T1 and T2 are both more than $7000 \mathrm{~km}$, and T4 is the traditional maritime channel which is the longest, but with the most mature and complete supporting facilities. In addition, the key nodes are typically well-connected and coordinated.

From the perspective of transportation time and costs, T3 has significant advantages. The estimated transportation time is 4 days, and the transportation costs are only USD $955 / 40 \mathrm{ft}$. The longest distance of T4 is $14,590 \mathrm{~km}$, but the freight is only USD $1400 / 40 \mathrm{ft}$, ranking the second at a unit price of USD $0.096 / \mathrm{km} / 40 \mathrm{ft}$. However, the freight rate along Yuxinou (Chongqing-Xinjiang-Europe Railway) is USD $0.55 / \mathrm{km} / 40 \mathrm{ft}$, which is about 5.7 times the marine route. It is clear that $\mathrm{T} 4$ has the lowest unit transport rate but takes the longest time. The estimated speeds of marine transportation and Yuxinou high-speed railway are $695 \mathrm{~km} /$ day and $733 \mathrm{~km} /$ day, respectively, which do not make much difference, indicating that the land-based highspeed railway transport is significantly delayed by customs clearance, loading, and other factors. In contrast, mature T4 has the advantage of efficient customs clearance. In the future, T1, T2, and T3 have significant room for improvement in customs clearance efficiency and other supporting facilities to tap into the speed advantage of high-speed railway.

From the perspective of domestic infrastructure of each corridor, T2 has the lowest score, and the infrastructure of Mongolia and the Far East of Russia are relatively poor, especially the Mongolian infrastructure ranks the lowest among the 12 countries in the four corridors.

\section{Methodology}

In the proposed hierarchical evaluation model of SVITC in this paper, the indicators at each level may not be completely independent. Therefore, this paper adopts a fuzzy integral method that can handle interrelated indicators at each level. In addition, the important index of fuzzy density in fuzzy integral is related to the weight of each index. Based on the hierarchical model, this article conceives that different countries at different stages of development have distinct preferences for their national interests and specific national conditions must be considered in the assessment process. Although the overall idea can be grasped relatively easily, the specific weights at different levels are hard to obtain and subjective human judgments are often inevitable. At the same time, this paper also uses an entropy weight method to evaluate objective weights. By integrating subjective and objective weights to obtain comprehensive weights, the approach in this paper can properly handle human judgment embedded in the subjective weights and bridge data to objective weights.

\subsection{Fuzzy Integral Method}

4.1.1. $\lambda$-Fuzzy Measure. Fuzzy measures are a prerequisite and key element of using a fuzzy integral method. Among different measures, a $\lambda$-fuzzy measure is a typical and widely used one. Its definition is as follows.

Definition 1. If a fuzzy measure $g$ satisfies the following properties: $\quad$ if $\quad A \cap B=\phi$, then $g(A \cup B)=g(A)+g(B)+\lambda g(A) g(B)$, where $\lambda \in[-1, \infty)$, then $g$ is called a $\lambda$-fuzzy measure or $g_{\lambda}$ measure. Let $X=\left\{x_{1}\right.$, $\left.x_{2}, \ldots, x_{n}\right\}$ be a finite set, and the fuzzy density function of each variable $x_{i}$ is $g\left(x_{i}\right)$, then $g_{\lambda}$ can be written as follows:

$$
\begin{aligned}
g_{\lambda}= & \left(\left\{x_{1}, x_{2}, \ldots, x_{n}\right\}\right)=\sum_{i=1}^{n} g\left(x_{i}\right)+\lambda \sum_{i 1=1}^{n-1} \sum_{i 2=i 1+1}^{n} g\left(x_{i 1}\right) \\
& +g\left(x_{i 2}\right)+\cdots+\lambda^{n-1} g\left(x_{1}\right) g\left(x_{2}\right), \ldots, g\left(x_{n}\right) \\
= & \frac{1}{\lambda}\left|\prod_{i=1}^{n}\left(1+\lambda g\left(x_{i}\right)\right)-1\right|, \quad \lambda \in[-1, \infty), \lambda \neq 0 .
\end{aligned}
$$

4.1.2. Fuzzy Integral. A fuzzy integral is a nonlinear function defined based on a fuzzy measure. It does not require mutual independence of evaluation indicators. Different fuzzy integrals have been proposed in the literature such as Suggeon fuzzy integral [36], Weber fuzzy integral [37], and Choquet fuzzy integral [38]. This paper will use the most widely used Choquet fuzzy integral as defined below. 
Definition 2. Let $f\left(x_{1}\right) \geq f\left(x_{2}\right) \geq \cdots \geq f\left(x_{i}\right) \geq \cdots \geq f\left(x_{n}\right)$, the Choquet fuzzy integral of the fuzzy measure $g$ of $f$ on $X$ is

$$
\int f \mathrm{~d}_{g}=f\left(x_{n}\right) g\left(X_{n}\right)+\left[f\left(x_{n-1}\right)-f\left(x_{n}\right)\right] g\left(X_{n-1}\right)+\cdots+\left[f\left(x_{1}\right)-f\left(x_{2}\right)\right] g\left(X_{1}\right)
$$

where $f\left(x_{i}\right)$ is the standardized ith index value of the evaluation object; $g\left(X_{i}\right)$ indicates the importance of simultaneously considering attributes $x_{1}, x_{2}, \ldots, x_{i}$. $g\left(X_{1}\right)=g\left(\left\{X_{1}\right\}\right), g\left(X_{n}\right)=g\left(\left\{X_{1}, X_{2}, \ldots, X_{n}\right\}\right)$.

4.2. Entropy Weight Method. Assuming that there are $m$ evaluation objects and $n$ evaluation indexes, the standardized dimensionless matrix of the original data is

$$
\begin{array}{r}
p=\left(p_{i j}\right)_{m \times n}, \quad 0 \leq p_{i j} \leq 1, \\
\sum_{i=1}^{m} p_{i j}=1, \quad i=1,2, \ldots, m, j=1,2, \ldots, n .
\end{array}
$$

For the index $x_{j}$, its information entropy is given as

$$
E_{j}=-k \sum_{i=1}^{m} p_{i j} \ln \left(p_{i j}\right),
$$

where $k=(1 / \ln m)$.

The entropy weight for the $j$ th index is defined as follows:

$$
W_{j}=\frac{1-E_{j}}{n-\sum_{i=1}^{n} E_{j}} .
$$

\subsection{Comprehensive Weight}

$$
\beta_{j}=\frac{\alpha_{j * W_{j}}}{\sum_{j=1}^{n} \alpha_{j * W_{j}}} .
$$

Here, $a_{j}$ is the subjective weight and $W_{j}$ is the objective weight calculated by the entropy weight method (equation (5)). Furthermore, by combining these two weights, we obtain a comprehensive weight $\beta_{j}$, which will be used as the fuzzy density in the fuzzy integral. According to the transfer function between the evaluation indexes, we can calculate the abovementioned correlation weights and the $g\left(X_{i}\right)$ value of each evaluation index.

\section{Evaluation of SVITC for the Four Corridors}

As discussed above, because different countries are often at different stages of development and have distinct preferences for the five values, they usually assign different weights as per their specific considerations. In addition, this paper analyzes and compares the strategic values of the four corridors from China's perspective.

\subsection{Data Sources for the Index of SVITC for the Four Corridors}

5.1.1. A Description of the Indexes in Assessing SVITC. Following Figure 1 in Section 2, we collect data for the following indexes from different sources based on their representativeness, authority, and availability. Table 2 describes the indicators and data selection.

In Table 2, the index $P_{1}$ needs further explanations: it represents how close the bilateral relationship between China and $\mathrm{Ti}$, and the qualitative assessment will be converted into the quantitative evaluation. Because of China's foreign policy of nonalignment, its bilateral relations have always been defined as different levels of "partnership" with other nations. According to the closeness of the bilateral relationship and the level of cooperation, different semantic rhetorics are employed to China's relations with other nations. By collecting the semantic differences between China and different countries since the establishment of diplomatic relations, the semantic differences are categorized into 9 levels, and the 11 countries in the four corridors are scored accordingly. The specific scores are shown in Table 4.

5.1.2. Original and Standardized Data of SVITC Indexes. The original and normalized data of SVITC indexes are shown in Table 5. Because the raw data are different in magnitudes and units, to facilitate a fair comparison and further processing, equation (3) is employed to standardize them. The three indexes, $C_{1}, C_{2}$, and $M_{2}$, require further explanations as follows.

$C_{1}$ represents the ability of cultural diffusion. At present, most scholars take Confucius Institutes as a representative of Chinese traditional culture, whose output represents the influence and diffusion power of Chinese culture [39-41]. $C_{2}$ stands for the value of tourism, measured by the number of tourists from Ti to China (in ten thousand). Because culture is the soul of tourism, the number of inbound tourists can thus represent the cultural attractiveness of a country, measured by $C_{2}$ here. However, because the national statistical data source only shows information on the top countries of inbound tourists to China, data are missing for seven of the eleven countries, especially no information is available for any country on the $\mathrm{T} 1$ corridor, meaning that the numbers of tourists from these nations are relatively low and below the threshold to be included in our statistical source. While each of the other three corridors has data for at least one nation, it is sensible to infer that T1 ranks the lowest in this metric among the four corridors. To handle missing original data in this dimension, we use the deduced ranking of T2, T4, T3, and T1 to obtain normalized data in this row. 
TABLe 2: Description of the indexes and data collection for assessing SVITC.

\begin{tabular}{|c|c|c|c|c|c|c|}
\hline \multicolumn{3}{|c|}{ Index } & \multirow{2}{*}{$\begin{array}{l}\text { Measurement index data selection and } \\
\text { units } \\
\begin{array}{c}\text { Number of Confucius Institutes and } \\
\text { Confucius Classrooms in Ti (unit) }\end{array}\end{array}$} & \multirow{2}{*}{$\begin{array}{l}\text { Contribution } \\
\text { Positive }\end{array}$} & Data sources & Remarks \\
\hline C & C & $C_{1}$ & & & $\begin{array}{l}\text { Information on the } \\
\text { Headquarters of the } \\
\text { Confucius Institute }\end{array}$ & $\begin{array}{l}\text { Confucius Institutes represent } \\
\text { Chinese Confucian culture }\end{array}$ \\
\hline & C & $\mathrm{C}_{2}$ & $\begin{array}{l}\text { Number of tourists from Ti to China } \\
\qquad(10,000 \text { people })\end{array}$ & Positive & $\begin{array}{l}\text { Data of the National Bureau } \\
\text { of Statistics of China in } 2018\end{array}$ & $\begin{array}{l}\text { The number of inbound tourists } \\
\text { symbolizes cultural attractiveness }\end{array}$ \\
\hline \multirow{4}{*}{$\mathrm{P}$} & $P$ & $P_{1}$ & $\begin{array}{l}\text { Positioning of relations between China } \\
\text { and Ti ( } 0-9 \text { points) }\end{array}$ & Positive & $\begin{array}{l}\text { https://www.fmprc.gov.cn/ } \\
\text { web/ and http://www. } \\
\text { mofcom.gov.cn/ }\end{array}$ & $\begin{array}{l}\text { Ratings are given based on whether a } \\
\text { bilateral relationship is established } \\
\text { and the closeness of the relationship }\end{array}$ \\
\hline & & $P_{21}$ & $\begin{array}{l}\text { Number of high-level interactions } \\
\text { between China and Ti after the } \\
\text { establishment of diplomatic ties (times) }\end{array}$ & Positive & $\begin{array}{l}\text { https://www.fmprc.gov.cn/ } \\
\text { web/ }\end{array}$ & $\begin{array}{l}\text { Total since establishment of } \\
\text { diplomatic relations up to } 2019\end{array}$ \\
\hline & & $P_{22}$ & $\begin{array}{c}\text { Number of high-level interactions } \\
\text { between China and Ti during the } \\
\text { period of B\&R (times) }\end{array}$ & Positive & $\begin{array}{l}\text { https://www.fmprc.gov.cn/ } \\
\text { web/ }\end{array}$ & Total from 2013 to 2019 \\
\hline & $P$ & $P_{3}$ & Political stability (0-100 points) & Positive & $\begin{array}{l}\text { World Economic Forum: } \\
\text { "Global Competitiveness } \\
\text { Report 2019" }\end{array}$ & Index 1.20 \\
\hline \multirow{3}{*}{$S$} & $S$ & $S_{1}$ & $\begin{array}{l}\text { National Health }(0-100 \text { points): } \\
\text { healthy life expectancy }\end{array}$ & Positive & $\begin{array}{l}\text { World Economic Forum: } \\
\text { "Global Competitiveness } \\
\text { Report 2019" }\end{array}$ & Index 5.01 \\
\hline & $S_{2}$ & $S_{21}$ & $\begin{array}{c}\text { Job security is characterized by the } \\
\text { unemployment rate }(\%)\end{array}$ & Negative & $\begin{array}{l}\text { World Economic Forum: } \\
\text { "Global Competitiveness } \\
\text { Report 2019" }\end{array}$ & $\begin{array}{l}\text { Statistics data on the unemployment } \\
\text { rate in } 2018\end{array}$ \\
\hline & $S$ & $S_{3}$ & $\begin{array}{l}\text { National security (0-100 points) } \\
\text { Measured from four aspects: organized } \\
\text { crime, homicide rate, terrorism } \\
\text { incidence, and reliability of police } \\
\text { services }\end{array}$ & Positive & $\begin{array}{l}\text { World Economic Forum: } \\
\text { "Global Competitiveness } \\
\text { Report 2019" }\end{array}$ & $\begin{array}{l}\text { Average weighting of indexes } \\
1.01-1.04\end{array}$ \\
\hline \multirow[t]{2}{*}{$M$} & $M$ & $\Lambda_{1}$ & $\begin{array}{l}\text { Military strength (the larger the } \\
\text { number, the stronger the strength) }\end{array}$ & Uncertain & $\begin{array}{l}\text { https://www. } \\
\text { globalfirepower.com/ }\end{array}$ & $\begin{array}{l}\text { Value, which can be positive or } \\
\text { negative, should be modified after } \\
\text { incorporating the } P_{1} \text { index }\end{array}$ \\
\hline & $M$ & $\Lambda_{2}$ & $\begin{array}{l}\text { The key nodes of the corridor are used } \\
\text { as the score of the military port }\end{array}$ & Positive & $\begin{array}{l}\text { Analysis carried out by the } \\
\text { authors }\end{array}$ & $\begin{array}{l}\text { See the corresponding explanations in } \\
\text { Section 5.1.2 }\end{array}$ \\
\hline \multirow{5}{*}{ E } & & $E_{11}$ & $\begin{array}{l}\text { Labor Force size in } \mathrm{Ti} \text { (ten thousand } \\
\text { people) }\end{array}$ & Positive & $\begin{array}{l}\text { International data from the } \\
\text { National Bureau of Statistics } \\
\text { of China }\end{array}$ & $\begin{array}{l}\text { Use data from the most recent year of } \\
\qquad 2015\end{array}$ \\
\hline & $E_{1}$ & $E_{12}$ & $T_{i}$ technology (0-100 points) & Positive & $\begin{array}{l}\text { World Economic Forum: } \\
\text { "Global Competitiveness } \\
\text { Report 2019" }\end{array}$ & $\begin{array}{c}\text { The innovation capability of index } \\
\text { 12.0 represents the technology level of } \\
\mathrm{Ti}\end{array}$ \\
\hline & & $E_{13}$ & $\begin{array}{l}T_{i} \text { state energy: to measure the total } \\
\text { production of primary energy }\end{array}$ & Positive & https://cn.knoema.com & Use data in 2017 \\
\hline & $E_{2}$ & $E_{21}$ & $\begin{array}{l}\text { Total value of import and export trade } \\
\text { during the period of B\&R (USD } 100 \\
\text { million) }\end{array}$ & Positive & $\begin{array}{l}\text { Data from the National } \\
\text { Bureau of Statistics of China }\end{array}$ & $\begin{array}{l}\text { Reflecting the economic and trade } \\
\text { reality between China and } \mathrm{Ti} \text { after } \\
\text { implementing the } \mathrm{B} \& \mathrm{R} \text { initiative }\end{array}$ \\
\hline & $E_{3}$ & $E_{31}$ & $\begin{array}{l}\text { Total of net FDI inflows in Ti over } \\
2014-2017 \text { years (USD millions) }\end{array}$ & Positive & $\begin{array}{l}\text { UNCTAD: “World } \\
\text { Investment Report 2018" }\end{array}$ & $\begin{array}{l}\text { Reflect expected economic growth in } \\
\qquad \mathrm{Ti}\end{array}$ \\
\hline
\end{tabular}

$T_{i}$ stands for country $i$ along the four corridors other than China.

$M_{2}$ is the logistics support capability of military stations at key nodes. The Gwadar Port in T1 has taken root and is regarded as a model of political mutual trust, thanks to the high-level relationship between China and Pakistan (8 points). Therefore, it can be considered as China's navy base and logistics supply base in the future, and we assign it a value of 1 point. At the same time, the Kyaukpyu Port in T3, after being delayed for three years, a framework agreement was signed in 2018. As China accounts for $70 \%$ of the shares and the relationship between China and Myanmar is at a relatively high level (7 points), it can also be considered as a military port and logistics supply point in the future. On the contrary, the Kyaukphyu Port in T3 is of great significance to China as analyzed earlier, but it remains at the blueprint stage and has to overcome significant extraterritorial resistance before coming to fruition, so it is assigned 0.5 points. The Straits of Malacca and the Piraeus Port in T4 are, respectively, assigned -1 and 1 for their contributions to $M_{2}$. In the context of the current Sino-US trade friction, given the close military cooperation between Singapore and US, the 
TABLE 3: Subjective weights' assignment.

\begin{tabular}{ll}
\hline Index weight distribution $(\%)$ & \\
\hline$C(20)=C_{1}(15)+C_{2}(5)$ & \\
$P(25)=P_{1}(10)+P_{2}(7.5)+P_{3}(7.5) ;$ & $P_{2}(7.5)=P_{21}(3.5)+P_{22}(4)$ \\
$S(25)=S_{1}(25 / 3)+S_{2}(25 / 3)+S_{3}(25 / 3) ;$ & \\
$M(15)=P_{1} \cdot M_{1}(7.5)+M_{2}(7.5)$ & $E_{1}(5)=E_{11}(1)+E_{12}(2)+E_{13}(2) ; E_{2}(5)=E_{21}(5) \quad$ \\
$E(15)=E_{1}(5)+E_{2}(5)+E_{3}(5) ;$ & \\
SVITC $=C(20)+P(25)+S(25)+M(15)+E(15)$ & \\
\hline
\end{tabular}

Strait of Malacca has actually served as a military port for the US Navy and is assigned a value of -1 point owing to its significant negative value for China. As for the Piraeus Port, as a China-Greece joint venture, COSCO Group won the bid to obtain 35-year franchise rights of its Pier 2 and Pier 3 in 2008 and acquired $67 \%$ equity in 2016. In the future, the Piraeus Port in Greece has well positioned a logistics supply base of Chinese naval ships, which will help to improve China's security and escort capability for cargo ships sailing to the Mediterranean, so it is assigned a value of 1 point.

Judging from the original data of the 11 countries in the four corridors, Russia ranks first most frequently and takes the first place for eight indicators. The next is Singapore, ranking the first for five indicators, especially in the social value dimension: healthy life expectancy $\left(S_{1}\right)$ and citizen safety and security $\left(S_{3}\right)$. Singapore's welfare of the people's livelihood has obvious advantages, consistent with its characteristics of the wealthy phase and its FDI inflow in 2014-2017 also ranks the first $\left(E_{31}\right)$, indicating that Singapore is also a hot spot for foreign investment. India has scored first twice, with the lowest unemployment rate and the most abundant labor force, and Pakistan and Greece, respectively, rank the first once in terms of military port security. In terms of the lowest ranking indicators, each of Bangladesh and Greece ranks at the bottom three times, followed by Singapore, Mongolia, Iran, and Pakistan with two lowest-ranking indicators each. Singapore ranks the lowest in military port $\left(M_{2}\right)$ and energy value $\left(E_{13}\right)$. Mongolia has the lowest score in labor value $\left(E_{11}\right)$ and FDI investment value $\left(E_{31}\right)$. Iran has the lowest score in the number of Confucius Institutes $\left(C_{1}\right)$ and high-level interactions $\left(P_{21}\right)$, where the low score in $P_{21}$ is partly due to the absence of statistical data prior to 2013 as noted in the footnote in Table 5. Pakistan scores the lowest in $S_{1}$ and $S_{3}$.

\subsection{Evaluation Steps and Results}

5.2.1. Subjective Weights Based on SVITC Hierarchy Theory. Without accounting for the development stage of a country, it is sensible to assign equal weights to the five criterion-level indexes with $20 \%$ each. However, according to the hierarchy theory, China is now at a well-off stage with social and geopolitical value taking more prominent positions. China's President Xi Jinping reported to the 19th National People's Congress: "as socialism with Chinese characteristics has entered a new era, the principal contradiction facing Chinese society has evolved. What we now face is the contradiction between unbalanced and inadequate development and the people's ever-growing needs for a better life [42]." Domestically, China's current focus is to improve people's livelihoods, so the weight of social value is set at $25 \%$; Internationally, China's B\&R initiative aims to promote collective development with partner nations, thereby gaining more recognition and respect from the international community. Therefore, a weight of $25 \%$ is assigned to the geopolitical value. Correspondingly, the weights of economic value and military value are adjusted to $15 \%$, and the weight of cultural value remains unchanged at $20 \%$. For the cultural value weight, due to lack of data for index $C_{2}$, we assign to it a lighter weight of $5 \%$, leaving the weight to $C_{1}$ at $15 \%$ and the ratio between them as $C_{1}: C_{2}=0.750: 0.250$. In the subsequent calculation, we divide the overall weight for the main indicators into the subindexes in the lower levels in a similar fashion. In geopolitics, $P_{1}$ is a principal indicator of the relationship between two countries, so it takes $10 \%$ of the $25 \%$ total weight allocated to $P$ with the remaining $15 \%$ weight equally split between the other two indicators, $P_{2}$ and $P_{3}$. For $P_{2}$, we assign $3.5 \%$ weight to $P_{21}$ and $4 \%$ to $P_{22}$. The key rationale behind this allocation is due to the consideration that bilateral relations are more closely related to changes in the current world situation and better characterized by the number of interactions during the period of $B \& R$, which are more representative and up to date. Several secondary and tertiary indicators of $S$ and $M$ are all equally weighted. The resource value of $E$ is equally divided into three indicators: labor, technology, and energy. For the secondary indicator $E_{11}$, as it only considers the number of labor without accounting for quality, its weight is reduced to $1 \%$ while the remaining two secondary indicators $E_{12}$ and $E_{13}$ are set at $2 \%$ each. The specific subjective weights assigned to all levels of indicators are shown in Table 3.

5.2.2. Objective Weights by the Entropy Method, Comprehensive Weights, $\lambda$-Value, and Calculation Steps. Using equations (4) and (5) of the entropy weight method, objective weights are calculated based on a bottom-up approach. For example, the lowest level indicators $\left(P_{21}, P_{22}\right)$ are calculated as follows: their objective weights are determined as $(0.501,0.499)$, and subjective weights are normalized as $(0.467=3.5 / 7.5,0.533=4 / 7.5)$. According to equation $(6)$, the comprehensive weights are calculated as $(0.467,0.533)$ by combining subjective and objective weights. Its value is the fuzzy integral of fuzzy density. Next, we use equation (1) to compute the fuzzy measure, which requires us to determine the critical $\lambda$-value first. Existing research shows that when $\lambda$ is positive, the evaluation focuses on balancing the 
TABLE 4: Evaluating the relationship positioning between China and Ti.

\begin{tabular}{lcc}
\hline Positioning of bilateral relations & Point & Countries along the corridors \\
\hline No diplomatic relations & 0 & NA \\
Partnerships & 1 & NA \\
Cooperative partnership & 2 & NA \\
Partnership of cooperation in all respects & 3 & Bangladesh \\
Comprehensive partnership of cooperation & 4 & Singapore \\
Strategic cooperative partnership & 5 & Indian, Turkey \\
Comprehensive strategic partnership & 6 & Greece, Egypt, Mongolia, Iran \\
Comprehensive strategic cooperative partnership & Myanmar \\
All-weather strategic cooperative partnership & 8 & Pakistan \\
Comprehensive strategic partnership of coordination & 9 & Russia \\
\hline
\end{tabular}

Data source: according to the information on the websites of the Ministry of Foreign Affairs and the Ministry of Commerce, PRC, the authors create this table.

TABLE 5: Raw and normalized data of SVITC for the four corridors and 11 countries.

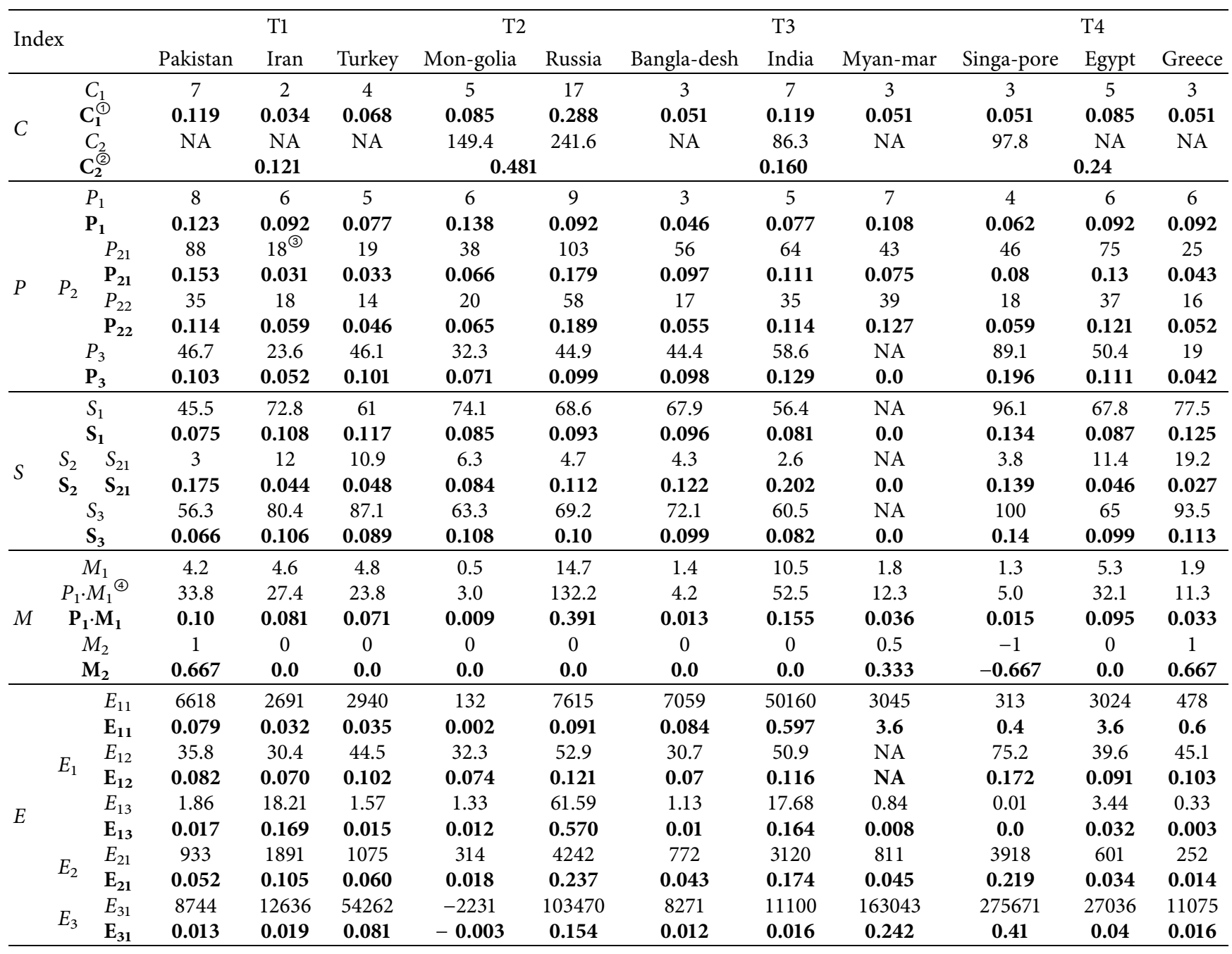

(1)The normalized value is represented by the index label in italics. The remaining indexes are similarly labelled in italic in this table. (2)Due to lack of inbound tourism data for seven countries, normalized data on this index are obtained by using the corridor ranking, $(4,1,3,2)$. (3) Iran and China established diplomatic relations in 1971, but the Ministry of Foreign Affairs of China recorded data on high-level exchanges between the two countries only since 2013. (4) The positioning relationship of $P_{1}$ is used to modify $M$, that is, a stronger military strength of Ti does not necessarily translate into a larger positive value as its relationship with China has to be considered.

indicators; when $\lambda$ is a small negative number, the evaluation takes into account some special indicators while balancing the indicators [43]. In this index system, the emphasis differs from the index layer to the criterion layer (such as $P_{1}, P_{2}$, and
$\left.P_{3} \Longrightarrow P\right)$ and the criterion layer as well as the target layer $(C$, $P, S, M$, and $E \Longrightarrow$ SVITC). The former considers the balanced development of all indicators, while the latter considers both balancing the relevant indicators and certain 
TABLE 6: Comparison of SVITC of the four corridors.

\begin{tabular}{|c|c|c|c|c|c|c|c|c|c|}
\hline \multirow{2}{*}{ Index } & \multirow{2}{*}{ Objective weights } & \multirow{2}{*}{ Subjective weights } & \multirow{2}{*}{ Comprehensive weights } & \multirow{2}{*}{$\lambda$} & \multirow{2}{*}{ Upper index } & \multicolumn{4}{|c|}{ Fuzzy integral value } \\
\hline & & & & & & $\mathrm{T} 1$ & $\mathrm{~T} 2$ & T3 & $\mathrm{T} 4$ \\
\hline $\begin{array}{l}P_{21} \\
P_{22}\end{array}$ & $\begin{array}{l}0.501 \\
0.499\end{array}$ & $\begin{array}{l}0.467 \\
0.533\end{array}$ & $\begin{array}{l}0.467 \\
0.533\end{array}$ & 0.5 & $P_{2}$ & 0.217 & 0.249 & 0.289 & 0.240 \\
\hline $\begin{array}{l}P_{22} \\
E_{11} \\
E_{12} \\
E_{13}\end{array}$ & $\begin{array}{l}0.459 \\
0.649 \\
0.296\end{array}$ & $\begin{array}{l}0.555 \\
0.200 \\
0.400 \\
0.400\end{array}$ & $\begin{array}{l}0.535 \\
0.028 \\
0.668 \\
0.304\end{array}$ & 0.5 & $E_{1}$ & 0.228 & 0.299 & 0.200 & 0.238 \\
\hline $\begin{array}{l}C_{1} \\
C_{2}\end{array}$ & $\begin{array}{l}0.530 \\
0.470\end{array}$ & $\begin{array}{l}0.750 \\
0.250\end{array}$ & $\begin{array}{l}0.772 \\
0.228\end{array}$ & 0.5 & $C$ & 0.185 & 0.397 & 0.214 & 0.192 \\
\hline $\begin{array}{l}P_{1} \\
P_{2} \\
P_{3} \\
\end{array}$ & $\begin{array}{l}0.336 \\
0.336 \\
0.329 \\
\end{array}$ & $\begin{array}{l}0.400 \\
0.300 \\
0.300 \\
\end{array}$ & $\begin{array}{l}0.403 \\
0.302 \\
0.296 \\
\end{array}$ & 0.5 & $P$ & 0.256 & 0.214 & 0.245 & 0.271 \\
\hline $\begin{array}{l}S_{1} \\
S_{2} \\
S_{3} \\
\end{array}$ & $\begin{array}{l}0.330 \\
0.336 \\
0.333 \\
\end{array}$ & $\begin{array}{l}0.333 \\
0.330 \\
0.333 \\
\end{array}$ & $\begin{array}{l}0.332 \\
0.334 \\
0.334 \\
\end{array}$ & 0.5 & $S$ & 0.275 & 0.195 & 0.223 & 0.296 \\
\hline $\begin{array}{l}M_{1} \\
M_{2} \\
\end{array}$ & $\begin{array}{l}0.992 \\
0.008\end{array}$ & $\begin{array}{l}0.500 \\
0.500\end{array}$ & $\begin{array}{l}0.992 \\
0.008\end{array}$ & 0.5 & $M$ & 0.253 & 0.396 & 0.201 & 0.139 \\
\hline $\begin{array}{l}E_{1} \\
E_{2} \\
E_{3} \\
\end{array}$ & $\begin{array}{l}0.346 \\
0.348 \\
0.306 \\
\end{array}$ & $\begin{array}{l}0.033 \\
0.033 \\
0.033 \\
\end{array}$ & $\begin{array}{l}0.347 \\
0.348 \\
0.306 \\
\end{array}$ & 0.5 & $E$ & 0.183 & 0.229 & 0.239 & 0.309 \\
\hline $\begin{array}{l}C \\
P\end{array}$ & $\begin{array}{l}0.196 \\
0.205\end{array}$ & $\begin{array}{l}0.200 \\
0.250\end{array}$ & $\begin{array}{l}0.195 \\
0.255\end{array}$ & & & & & & \\
\hline $\begin{array}{l}S \\
M \\
E\end{array}$ & $\begin{array}{l}0.203 \\
0.194 \\
0.203\end{array}$ & $\begin{array}{l}0.250 \\
0.150 \\
0.150\end{array}$ & $\begin{array}{l}0.253 \\
0.145 \\
0.151\end{array}$ & -0.5 & SVITC & 0.241 & 0.285 & 0.228 & 0.257 \\
\hline
\end{tabular}

special preferences due to different countries with diverse preferences for distinct values at various development stages.

Given these considerations, $\lambda$ is set at 0.5 below the criterion level to accommodate the balancing effect. While $\lambda$ takes a value of -0.5 to account for both "balance" and "particularity" in the criterion layer to the target layer. Therefore, for the index layer $\left(P_{21}, P_{22}\right), \lambda=0.5$, the fuzzy measure is calculated and normalized; then, the upper index value $P_{2}(0.217,0.249,0.289,0.240)$ is calculated based on equation (2). Following this procedure, the index weights and main results are shown in Table 6 . The comparison of each subindex of the four corridors is shown in Figure 4, and the comparison of SVITC of the four corridors is illustrated in Figure 5.

(1) Comparison of subindicators:

In the cultural value, T2 is far ahead (0.397) of the other three corridors whose scores are quite close to each other. This indicates that Chinese Confucian culture is the most influential in T2, but still needs more diffusion in the other three corridors. Especially in $\mathrm{T} 1$, the number of inbound tourists does not even show up in the statistical data source, indicating that China's cultural diffusion there is insignificant to attract tourists. In T3 and T4, China's cultural influence in Southeast and South Asia also need to be further strengthened along the corridors. In terms of social value, T4 leads the way, mainly thanks to Singapore's wealthy stage and high level of people's well-being. Especially, its values of $S_{1}$ and $S_{3}$ are outstanding even on a global scale and set up a model for China to learn. In terms of the military value, T2 has a significant advantage (0.396) owing to Russia's huge contribution, and $\mathrm{T} 1$ ranks the second with a comparative advantage, especially in the key node, the military port, the Gwadar Port has obvious strength. The Kyaukpyu Port of T3 is also likely to become a logistics depot in the future. T4 has the lowest military value mainly due to the negative impact of the Malacca Strait, but we should not overlook the positive contribution of the Piraeus Port in this corridor. In terms of economic value, T4 has a clear advantage, while $\mathrm{T} 1$ is the weakest. The four corridors are basically equal in geopolitical value, indicating that, during the period of $B \& R$, China equally values the political contributions from the four corridors and aims to expand its circle of friends.

(2) Comparison of overall indicators:

From the criterion level in Table 6 , the calculated comprehensive weights for $C, P, S, M$, and $E(0.195$, $0.255,0.253,0.145,0.151)$ are basically consistent with their subjective weights $(0.20,0.25,0.25,0.15$, $0.15)$. As mentioned earlier, we assign subjective weights according to the SVITC hierarchy theory. This confirms the rationality of setting weights based on this theory in combination with specific national conditions.

As Figure 5 indicates, the annular ratio of the strategic value of the four corridors is basically in the mean distribution state. The overall strategic values of 


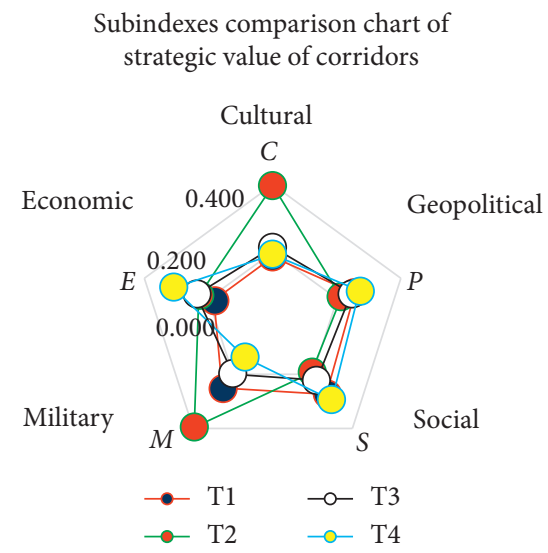

Figure 4: Comparison of SVITC for T1, T2, T3, and T4 by subindexes.

Comparison chart of the SVITC
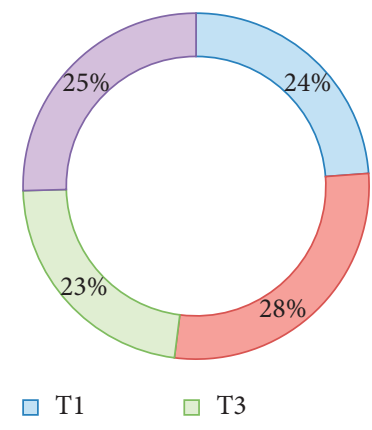

$\square \mathrm{T} 2 \quad \square \mathrm{T} 4$

Figure 5: Loop comparison chart of SVITC for T1, T2, T3, and T4.

the four corridors are as follows: T2 (0.285) takes a slight lead, followed by T4 (0.257), T1 (0.241), and finally T3 (0.228). This can be used as the basis for our strategic decisions. In addition, T2 and T4 are currently in operation and can be upgraded at a later stage. So, further investment in these two corridors is not as urgent as the current work-in-progress $\mathrm{T} 1$ and T3 lines. Since T1 and T3 are also of strategic importance and need more urgent funding to bring them online. So, if sufficient financial resource is available, they should both be prioritized in receiving investment. Otherwise, if limited is available for B\&R construction, $\mathrm{T} 1$ should be invested first.

\section{Discussion and Conclusions}

(1) The calculated comprehensive weights are consistent with the subjective weights, which shows the rationality of setting weights according to the hierarchy model and the specific national development stage, indicating that SVITC does have preferences at five levels. At present, China's emphases are indeed on the geopolitical and social values.

(2) From the perspective of reinvigorating the ancient Silk Road, the Northern and Maritime Silk Roads have been completely restarted and in operation as the T2 and T4 corridors. In addition, the "China-Pakistan" part of T1 has also been restarted and its demonstration and model effects are significant. Nevertheless, the "IranTurkey" part of T1 still has to be further pushed. The overall progress of T3 is very slow with $90 \%$ of the corridor remaining at the blueprint stage. This development is consistent with the ranking result of the strategic values of the four corridors in this study.

(3) The strategic value of T2 ranks at the top, which is largely attributed to the model relations between China and Russia. Russia has the largest number of Confucius Institutes, the highest level of relationship positioning ( 9 points), the largest number of highlevel interactions, the largest bilateral trade scale, and the strongest military strength. The positioning of a comprehensive strategic cooperative partnership is indeed the best annotation for this important bilateral relationship. It is apparent that Russia is the key factor to ensure smooth operations of T2, but the role of Mongolia as another neighboring country cannot be ignored, either. Mongolia's economy is under pressure with the lowest infrastructure index among the 12 countries in the four corridors. Due to China's apparent infrastructure strengths, abundant 
opportunities exist for the two nations to cooperate to improve Mongolia's infrastructure and combat its economic depression, thereby embracing breakthroughs to bridging geopolitical gaps and promoting communications between the peoples.

(4) T4 ranks second in the strategic value thanks to its superb performance in economic and social values as well as slight outperformance in geopolitical value. As a traditional corridor with mature supporting systems, it has the highest customs clearance efficiency, which sets up a model for other corridors. In the future, more investment is needed to transform and upgrade its aging infrastructure. Moreover, its negative value can be further mitigated by promoting the common mainstream Confucian culture between China and Singapore. A sensible strategy for China to accomplish this goal is to increase cultural exchanges and cooperation with Singapore, thereby enhancing mutual trust and promoting mutual understanding between the peoples.

(5) Although T1 ranks third, it is actually the leading corridor under construction. Its strategic value is basically equal to the T2 and T4 that are currently in operations. One can see that it is strongly supported by Pakistan and the Gwadar Port has great potential in military and economic value. In the future, $\mathrm{T} 1 \mathrm{can}$ be integrated into multimodal transport of "railway + waterway" or "Iron Silk Road." If the standard gauge is adopted in the planed China-Pakistan Railway, it can be conveniently integrated into T1 and T4 in Serbia upon its completion. If this grand blueprint is accomplished, it can unleash the great potential of the high-speed corridor connecting the Far East to the European hinterland.

(6) T3 is divided into two steps, which is highly feasible and can be an operational solution. The ChinaMyanmar channel will lead first, followed by the Bangladesh-India channel. Firstly, the relationship positioning between China and Myanmar is ranked third (7.0). Secondly, the Kyaukpyu Port is the most dazzling pearl in the four corridors. Moreover, the China-Myanmar oil and gas pipelines can serve as foreshadowing of what a successful Kyaukpyu Port may benefit the economy and people in Myanmar. Finally, it seems that the east line of China-Myanmar "herringbone" railway will motivate the construction of the west line of China-Myanmar "herringbone" railway in the future. Distinctly, the China-Myanmar channel has a solid foundation owing to the good bilateral relations. However, it should be noted that the diplomatic relations between United States and Myanmar have been resumed since the US announcing its "Asia-Pacific Strategy" in 2012. Furthermore, due to the disruption caused by Japan's involvement in 2014, it is important to pay attention to potential external influences from other sources.
(7) At the same time, the second half of T1, T3, and T4 can be integrated in the future. Only the Gwadar port is insufficient to satisfy the supply demand of China's ocean-going military ports and more port infrastructure is needed to provide adequate supports. Therefore, it is necessary to build more military ports at other key nodes. Upon their full operations, the Gwadar Port, the Kyaukpyu Port, and the Piraeus Port can form a conglomerate to fulfill this task by capitalizing on their complementary support to each other and ensure corridor and national security.

(8) Upon the completion of the four corridors, the Northwest, North, South, and Maritime Silk Roads will be reinvigorated and in full operations, which will presumably facilitate each country along the $B \& R$ to tap on its potentials and achieve the third stage of development, leading to these countries' self-realization with a strengthened sense of mission and calling rooted in the national blood. This vision also presents a valuable window of opportunity for a grand integration of different national cultures. Above the level of self-realization of the SVITC hierarchy model, there should be a superego that transcends self-realization, that is, a superego that breaks through the boundaries of ethnic groups, countries, and cultures, thereby bridging across the borders of different national interests and facilitating realization of the common interests of all mankind or building of the "community of human destiny."

\section{Data Availability}

The data used to support the findings of this study are included in the article.

\section{Conflicts of Interest}

The authors declare that there are no conflicts of interest.

\section{Acknowledgments}

This paper was supported by the National Social Science Foundation of China (no. 16AGJ007) and Humanities and Social Science Planning Project of Education Commission of Chongqing, China (no. 19SKGH134).

\section{References}

[1] T. Fallon, "The new silk road: Xi Jinping's grand strategy for Eurasia," American Foreign Policy Interests, vol. 37, no. 3, pp. 140-147, 2015.

[2] World Economic Forum, "US $\$ 8$ trillion needed to bridge ASEAN's infrastructure gap," 2020, https://www.weforum.org/ press/2014/05/us-8-trillion-needed-to-bridge-aseansinfrastructure-gap/.

[3] M. B. Regmi and S. Hanaoka, "Assessment of intermodal transport corridors: cases from north-east and central Asia," Research in Transportation Business \& Management, vol. 5, pp. 27-37, 2012.

[4] J. Berechman, D. Ozmen, and K. Ozbay, "Empirical analysis of transportation investment and economic development at 
state, county and municipality levels," Transportation, vol. 33, no. 6, pp. 537-551, 2006.

[5] E. Vinokurov and T. Tsukarev, "The belt and road initiative and the transit countries: an economic assessment of land transport corridors," Area Development and Policy, vol. 3, no. 1, pp. 93-113, 2018.

[6] D. Donaldson, "Railroads of the Raj: estimating the impact of transportation infrastructure," American Economic Review, vol. 108, no. 4-5, pp. 899-934, 2018.

[7] C. N. Berg, U. Deichmann, Y. Liu, and H. Selod, "Transport policies and development," The Journal of Development Studies, vol. 53, no. 4, pp. 465-480, 2017.

[8] J. J. Laird and A. J. Venables, "Transport investment and economic performance: a framework for project appraisal," Transport Policy, vol. 56, pp. 1-11, 2017.

[9] A. Quium, "Transport corridors for wider socio-economic development," Sustainability, vol. 11, no. 19, p. 5248, 2019.

[10] M. Alam, M. H. Dappe, M. Melecky et al., Wider Economic Benefits of Transport Corridors: Evidence from International Development Organizations, The World Bank, Washington, DC, USA, 2019.

[11] M. Roberts, M. Melecky, T. Bougna, and Y. Xu, "Transport corridors and their wider economic benefits: a quantitative review of the literature," Journal of Regional Science, vol. 60, no. 2, pp. 207-248, 2020.

[12] H. Hahm and S. Raihan, "The belt and road initiative: maximizing benefits, managing risks-a computable general equilibrium approach," Journal of Infrastructure, Policy and Development, vol. 2, no. 1, pp. 97-115, 2018.

[13] Y.-C. Chang and M. I. Khan, "China-Pakistan economic corridor and maritime security collaboration: a growing bilateral interests," Maritime Business Review, vol. 4, no. 2, pp. 217-235, 2019.

[14] H. S. Wang and Y. Q. Zhu, "A comparative study on the orientation of strategic values in the construction of ChinaMongolia-Russia economic corridor," Northern Economy, vol. 9, pp. 54-57, 2015.

[15] M. W. Lin, "China-Nepal-India economic corridor: its strategic significance and developing model," Modern International Relations, vol. 2, pp. 31-39, 2017.

[16] X. G. Li and L. Z. Sun, "The strategic value and security situation of the China-Pakistan economic corridor," People's Forum. Academic Frontiers, vol. 12, pp. 32-50, 2015.

[17] M. Zubir, The Strategic Value of the Strait of Malacca, Analysis Paper, Maritime Institute of Malaysia, Kuala Lumpur, Malaysia, 2004.

[18] H. Y. Malik, "Strategic importance of Gwadar port," Journal of Political Studies, vol. 19, no. 2, 2012.

[19] X. T. Yang, B. H. Jiao, S. H. Li et al., "Strategic value evaluation of sea lanes based on remote sensing and GIS method," Geography and Geographic Information Science, vol. 1, pp. 47-52, 2018.

[20] H. X. Zhang, Y. X. Liu, M. C. Li et al., "Strategic value assessment of oil and gas exploitation in the central and southern South China sea," Resources Science, vol. 11, pp. 2142-2149, 2013.

[21] W. Y. Cheng, Y. X. Liu, M. C. Li et al., "Strategic value evaluation of the atolls in the eastern Nansha islands based on AHP and fuzzy comprehensive evaluation method," Tropical Geography, vol. 33, no. 4, pp. 381-386, 2013.

[22] S. L. Yang and H. P. Gao, "BCIM economic cooperation and the forging of geopolitical reality of China," Indian Ocean Economy Research, vol. 2, pp. 70-83, 2014.
[23] Y. L. Yin, "Route Research of BCIM economic corridor," Yunnan Social Sciences, vol. 1, pp. 73-77, 2016.

[24] C. R. Smit and D. Snidal, The Oxford Handbook of International Relations, Oxford University Press, Oxford, UK, 2010.

[25] H. W. Li, "Four-dimensional perspective of strategic value," Technical Economics and Management Research, vol. 2, p. 42, 2014.

[26] P. Kennedy, The Great Strategy of War and Peace, World Knowledge Press, Boston, MA, USA, 2005.

[27] K. N. Waltz, "Reflections on theory of international politics: a response to my critics," in R. O. Keohane (ed.), Neorealism and its Critics, Columbia University Press, pp. 322-345, New York, NY, USA, 1986.

[28] Y. Z. Wang, World Politics-Views from China: National Interests, New World Press, Generation Sequence, Beijing, China, 2007.

[29] X. T. Yan, An Analysis of China's National Interests, Tianjin People Press, Tiajin, China, 1997.

[30] A. Kortunov, Russian National Interests: The State of Discussion, Russia's Place in Europe: a Security Debate, Peter Lang, Bern, Switzerland, 1999.

[31] T. Sun and C. M. Liu, "Culture attributes in shaping the vision of international order-on the cultural origin of "the building of a community with a shared future for mankind," Journal of Pacific Science, vol. 2, p. 17, 2019.

[32] F. Gao and X. Ma, "What we can learn from the hierarchy of needs in studying foreign policy making," International Forum, vol. 12, no. 1, pp. 51-56, 2010.

[33] A. H. Maslow, "A theory of human motivation," Psychological Review, vol. 50, no. 4, pp. 370-396, 1943.

[34] C. F. Wang and C. F. Huang, "Research on the cultural value of the CPIT international transportation corridor," Pacific Journal, vol. 26, no. 5, pp. 40-50, 2018.

[35] W. X. Lin, "The Road of "shellfish coin" and its significance in the study of Yunnan frontier history," The Study of Frontier History and Geography in China, vol. 23, no. 1, pp. 1-9, 2013.

[36] M. Sugeno, Fuzzy Measurement and Fuzzy Integrals: A Survey in Fuzzy Automata and Decision Processes, North-Holland Publishing, Amsterdam, Netherlands, 1977.

[37] S. Weber, "Decomposable measures and integrals for Archimedean t-conorm," Journal of Mathematical Analysis and Applications, vol. 101, no. 1, pp. 114-138, 1984.

[38] T. Murofushi and M. Sugeno, "An interpretation of fuzzy measures and the Choquet integral as an integral with respect to a fuzzy measure," Fuzzy Sets and Systems, vol. 29, no. 2, pp. 201-227, 1989.

[39] M. J. Xie, T. S. Wang, and R. M. Cui, "Does China's cultural output promote outward foreign direct investment?-An empirical test based on the development of Confucius Institute," Economics (Quarterly), vol. 16, no. 4, pp. 167-188, 2017.

[40] Y. M. Chen, Q. K. Sun, and X. Y. Zhang, "Will Confucius Institute promote outward foreign direct investment?-Based on the panel data of the countries along "The Belt and Road," International Trade Issues, vol. 8, pp. 84-95, 2017.

[41] B. J. Wang and Y. M. Chen, "Overview of international investment in 2017," World Economic Yearbook, vol. 1, pp. 402-421, 2018.

[42] China Daily, "Full text of Xi Jinping's report at 19th CPC National Congress," 2020, https://www.chinadaily.com.cn/ china/19thcpcnationalcongress/2017-11/04/content_ 34115212.htm.

[43] J. H. Sun, J. Hu, and Z. Liu, "A new criterion for $\lambda$-fuzzy measure and its application," Computer Engineering and Applications, vol. 19, pp. 249-255, 2014. 